\title{
Mucinous Adenocarcinoma, Endocervical Type
}

National Cancer Institute

\section{Source}

National Cancer Institute. Mucinous Adenocarcinoma, Endocervical Type. NCI

Thesaurus. Code C66953.

A mucinous adenocarcinoma characterized by the presence of malignant glandular cells which resemble the endocervical epithelium. 